\title{
Title
}

\section{Clinical facilitators' experience of near peer learning in Australian undergraduate nursing students: a qualitative study}

\section{Authors}

Associate Professor Saras Henderson, PhD, MEd, BAppSc (Nursing), RN, School of Nursing and Midwifery, Griffith University, The Hopkins Centre Research for Rehabilitation and Resilience; Women's Wellness Research Group, Menzies Health Institute QLD, Australia. Address: School of Nursing and Midwifery, Gold Coast campus, Griffith University, Southport Queensland 4222; Contact details: Telephone +61 07 55528910; Fax + 6107 55528526; Email s.henderson@griffith.edu.au orcid.org/0000-0002-0757-6948

Dr Judith Needham EdD, MNursMan, RN, RM, School of Nursing and Midwifery, Griffith University, QLD Australia.

Address: School of Nursing and Midwifery, Logan campus, Griffith University, University Drive, Meadowbrook Queensland 4131; Contact details: Telephone +61 0733821158

Email: j.needham@griffith.edu.au

Professor Thea van de Mortel, RN PhD, School of Nursing and Midwifery, Griffith University, QLD, Australia.

Address: School of Nursing and Midwifery, Gold Coast campus, Griffith University, Southport Queensland 4222; Contact details: Telephone +61 07 55527855; Fax: +61 075552 8526

Email: t.vandemortel@griffith.edu.au 


\section{Corresponding Author:}

Associate Professor Saras Henderson, School of Nursing and Midwifery, Griffith University, Menzies Health Institute QLD, Australia.

Contact details: Telephone: +61 07 55528910; Fax: +61 07 55528526; Email s.henderson@griffith.edu.au

\section{Funding Source}

The Australian Collaborative Education Network Limited for a grant of $\$ 10,000$

\section{Conflict of Interest}

There is no conflict of interest

\section{Ethical Approval}

Ethics approval was granted by the University's Human Research Ethics Committee (Approval No. 2017/656)

\section{Acknowledgements}

The authors would like to thank the participant clinical facilitators who willingly gave their time to be involved in this study. The authors would also like to thank the Australian Collaborative Education Network Limited for a grant to support this research. 
Manuscript Number: NET_2020_61

Clinical facilitator's experience of near peer learning in Australian undergraduate nursing students: a qualitative study

\section{Dear Reviewers/Editor}

Thank you for your valuable constructive comments to improve the clarity and readability of our manuscript. Please fine below a table that shows the changes we have made in response to the reviewers' comments. We have highlighted the changes in the body of the revised manuscript.

\begin{tabular}{|c|c|}
\hline Reviewer \#1 & \\
\hline $\begin{array}{l}\text { This study provides very good information. I } \\
\text { have several suggestions that I think will } \\
\text { improve the readability and understanding of } \\
\text { the manuscript. I would also suggest that } \\
\text { references be less than } 10 \text { years old unless they } \\
\text { are related to theories or tools. I would also } \\
\text { add limitations of the study including the small } \\
\text { sample size and areas for further research. }\end{array}$ & $\begin{array}{l}\text { We have updated the references that were } \\
\text { over } 10 \text { years old throughout the manuscript } \\
\text { except for Bandura (1979) and Vygotsky } \\
\text { (1978) because these are seminal work on } \\
\text { theories. } \\
\text { We did not update Weyrich et al. (2008) } \\
\text { article as we could not find another later } \\
\text { article to replace it. } \\
\text { We have updated the reference list } \\
\text { accordingly. } \\
\text { Limitations of the study has been added. }\end{array}$ \\
\hline $\begin{array}{l}\text { 1). I would add something to the very first } \\
\text { sentence of the manuscript to make it more } \\
\text { profound. }\end{array}$ & $\begin{array}{l}\text { The sentence "Little research exists on clinical } \\
\text { facilitators' experience of using near-peer } \\
\text { learning in nurse education" has been added as } \\
\text { the first sentence of the manuscript. }\end{array}$ \\
\hline $\begin{array}{l}\text { 2). In the } 2 \text { nd paragraph of the introduction } \\
\text { delete the word "Although" }\end{array}$ & The word 'Although' has been deleted. \\
\hline $\begin{array}{l}\text { 3). Rephrase 1st sentence in 3rd paragraph of } \\
\text { the background section: "Studies on near-peer } \\
\text { learning have been on the views of students } \\
\text { and only a handful have focused on clinical } \\
\text { facilitator views". Change to "Studies on near- } \\
\text { peer learning have been based on the views of } \\
\text { students and only a few have focused on the } \\
\text { views of clinical facilitators". }\end{array}$ & Suggested change made in $3^{\text {rd }}$ paragraph. \\
\hline $\begin{array}{l}\text { 4) In same paragraph as above. Change "which } \\
\text { can negatively impact on student learning } \\
\text { outcomes." to "which can negatively impact } \\
\text { student learning outcomes." }\end{array}$ & Suggested change made in $3^{\text {rd }}$ paragraph. \\
\hline $\begin{array}{l}\text { 5) The first sentence of the 4th paragraph in } \\
\text { background section that begins "Despite } \\
\text { literature...." is too long. Split into } 2 \text { sentences } \\
\text { for clarity. }\end{array}$ & $\begin{array}{l}\text { This first sentence has been split into two } \\
\text { sentences as suggested. }\end{array}$ \\
\hline
\end{tabular}




\begin{tabular}{|c|c|}
\hline $\begin{array}{l}\text { 6) In same paragraph, change this sentence } \\
\text { "Carrell et al. (2013) reports that students tend } \\
\text { to gravitate towards others who are at the } \\
\text { same education level to themselves rather than } \\
\text { those at a more advanced level, which can } \\
\text { impact on junior students....." to "Carrell at al. } \\
\text { (2013) report that ................................ } \\
\text { impich can } \\
\text { suggested junior students. The bold indicates } \\
\text { bit long and could be divided into } 2 \text { sentences. }\end{array}$ & $\begin{array}{l}\text { Changes made and the sentence has been split } \\
\text { into } 2 \text { as suggested. }\end{array}$ \\
\hline $\begin{array}{l}\text { 7) In Ethical considerations, should the } \\
\text { University be named? I would not think so. }\end{array}$ & $\begin{array}{l}\text { University name has been removed as } \\
\text { suggested. }\end{array}$ \\
\hline $\begin{array}{l}\text { 8) I believe it would be good to mention a few } \\
\text { skills that the 3rd year students observed. Only } \\
\text { one (blood sugar level) is mentioned. }\end{array}$ & $\begin{array}{l}\text { Other examples that the } 3^{\text {rd }} \text { year students } \\
\text { observed have been included. }\end{array}$ \\
\hline $\begin{array}{l}\text { 9) In the Participants section, state that the } \\
\text { participants were clinical facilitators. }\end{array}$ & $\begin{array}{l}\text { The participants as being 'clinical } \\
\text { facilitators' is now included as suggested. }\end{array}$ \\
\hline $\begin{array}{l}\text { 10) In the methodological considerations where } \\
\text { you are describing how you analyzed the data } \\
\text { you provide the (Enosh and Ben-Ari, 2015) } \\
\text { reference. This was what you did. If the authors } \\
\text { in the reference recommended this type of } \\
\text { analysis state as recommended by or supported } \\
\text { by. }\end{array}$ & $\begin{array}{l}\text { This suggestion was taken on board and } \\
\text { change made accordingly. }\end{array}$ \\
\hline $\begin{array}{l}\text { 11) In the discussion section, the Anderson \& } \\
\text { Morgan reference is used but the information is } \\
\text { related to information from the clinical } \\
\text { facilitators from your study. I believe that } \\
\text { information from the clinical facilitators } \\
\text { supports that provided by Anderson \& Morgan } \\
\text { or is consistent with so I would clarify that. }\end{array}$ & The suggested change has been made. \\
\hline $\begin{array}{l}\text { 12) Also in the discussion section: This sentence } \\
\text { is referenced "This situation created stress for } \\
\text { the facilitator as they were accountable for the } \\
\text { learning outcomes of the first-year student" } \\
\text { (Mamhidir et al., 2014). This information is } \\
\text { from your results so add why the reference is } \\
\text { there. Is it consistent with information from } \\
\text { Mamhidir? I would just clarify. }\end{array}$ & $\begin{array}{l}\text { Thank you, the reference to Mamhidir has } \\
\text { been edited to reflect the suggestion made } \\
\text { by the reviewer. Yes, the information from } \\
\text { Mamhidir is consistent with our result. }\end{array}$ \\
\hline
\end{tabular}




\begin{abstract}
Background: To mitigate escalating costs in clinical supervision of undergraduate nursing students and alleviate clinical facilitators' teaching burden, the near-peer learning model has become popular. Studies on near-peer learning have been on students' views of the model with a paucity of literature on clinical facilitators' experiences.
\end{abstract}

Aim: To explore clinical facilitator experiences of the near-peer learning model.

Design: A qualitative descriptive design was used with a purposeful sample of clinical facilitators involved in near-peer learning of nursing students.

Setting: Two teaching hospitals participated. Two medical and two surgical wards were selected from each.

Participants: Eleven clinical facilitators who had experienced using near-peer learning.

Methods: Focus group and individual interviews were conducted with clinical facilitators using a semi-structured interview guide following ethics approval. Data were analysed using content analysis.

Results: Four themes emerged: 1) Congruent student dyad characteristics 2) Clinical facilitator attributes of confidence in students' knowledge and effective time and conflict management, 3) Availability of suitable skills, and 4) Facilitator support and preparation on the model. These themes appear to promote optimum learning outcomes of the near-peer model including empowering students, junior students gaining practice in foundation skills and senior students gaining competence in leadership, mentoring and nurturing skills. Barriers included incongruent student characteristics resulting in conflict and trust issues, senior student not knowing how to teach, give feedback or teaching inaccurate information; facilitator's lack of 
Paper for Nurse Education Today 2020

confidence in students' knowledge level, inadequate time to manage the student dyad and resolve conflict; inadequate support and preparation from university staff; and unavailability of suitable skills.

Conclusion: Successful implementation requires careful selection of student dyads, appropriate clinical environment and support for clinical facilitators. Our findings provide a better understanding of the near-peer model for future implementation. 


\section{Introduction}

Little research exists on clinical facilitators' experience of using near-peer learning in nurse education. Peer learning has been used to educate health professional students (Stone et al., 2013). Whilst peer learning has been popular in medical education, nursing schools are beginning to use peer learning-(Boud, 2001) (Buell et al., 2018). This may be due to the escalating costs of clinical supervision leading to increases in the clinical facilitator to student ratio, potentially impacting on the quality of supervision and learning outcomes (Sevenhuysen et al., 2015).

Although-Many terms are interchangeably used in the literature to describe peer learning such as 'cooperative learning, peer mentoring, peer coaching, team learning, near-peer learning, peer tutoring and peer-assisted learning' (Stone et al., 2013, p. 1), this study uses the term near peer-learning, which involves a student from the same program teaching a student who is at a lower level in their education (McKenna and Williams, 2017). While there are studies on students' perspectives of near-peer learning, there is a paucity of research on clinical facilitators' perspectives of using this model with undergraduate nursing students. Clinical facilitators are the link between universities and the clinical environment and play a role in teaching clinical skills and supporting students to meet registration standards (Edgar \& Connaughton, 2014). It is important to understand clinical facilitators' views on near-peer learning to provide a comprehensive account to improve its implementation.

\section{Background}

As the number of students entering nursing continue to rise, nursing schools are beginning to use near-peer learning as an adjunct to standard supervision models. The nearpeer learning model involves senior students teaching junior students from the same education 
program (McKenna and Williams, 2017). In the model, the clinical facilitator takes on a supportive and an overseer role (Palsson et al., 2017). Literature suggests that the near-peer model helps to improve learning outcomes for junior students and promotes communication and leadership skills in senior students (Silberberg et al., 2013). Blomberg et al. (2014) report that junior students' stress levels also reduce through working with senior peers (Stenberg and Carlson, 2015).

Near-peer learning encompasses aspects of social learning theory (Bandura, 1979) and Vygotsky's social interaction and the zone of proximal development constructivist theory (1978). The focus of social learning theory is that people learn through interaction with others and that learning is reciprocal (Bandura, 1979). Vygotsky (1978) focuses on the sociocultural context and the connections between people. Within the clinical environment, the sociocultural context can facilitate the sharing of experiences between students making concepts easier to understand than if they are instructed by a skilled teacher. Tai et al. (2014) explain this is because junior students are more open to learning from a senior peer who has already achieved the competency in the skill the junior student is trying to learn. Vygotsky reports how learning occurs in the zone of proximal development - defined as the difference between what the learner can do independently and what they can do under the guidance of a skilled teacher or through collaboration with a senior peer (Tai et al., 2014).

Studies on near peer learning have been on the views of students and only a handful have focused on clinical facilitator views Studies on near-peer learning have been based on the views of students and only a few have focused on the views of clinical facilitators. A study by Sevenhuysen et al. (2014) compared physiotherapy clinical educators' views on near-peer learning compared to the traditional model of clinical teaching where one teacher is responsible for a designated group of students at the same educational level. Clinical educators 
found near-peer learning reduced teaching burden as students could ask their peers questions about patient care. This provided educators downtime to concentrate on other aspects of their work. The educators reported near-peer learning helped students to develop skills in collaboration (Sevenhuysen et al., 2014), which they perceived to be valuable upon registration. Although feedback given by the peer teacher was viewed as beneficial, clinical educators in Sevenhuysen's study reported that peer feedback can be superficial and lack relevance,-which can negatively impact on student learning outcomes which can negatively impact student learning outcomes. Tai et al. (2014) concur, expressing reservations about student peer teachers' ability to give feedback to the student peer. Weyrich et al. (2008) add that near-peer learning may strain friendships between students and promote competition rather than collaboration although Durán et al. (2012) argue that competition may not be an issue when the student dyad is at different levels of education.

Despite literature highlighting how peer teaching enhances student learning and reduces clinical facilitator teaching load, Stone et al. (2013) stress student supervision by facilitators is important. Supervision as they can provide a safety net when the student peer cannot pass accurate information to their peer or does not possess suitable teaching skills, which could potentially impact on the provision of safe patient care (Stone et al., 2013). Riese et al. (2012) found that for peer learning to be useful the relationship between the student dyad needs to be considered and be integral to the deployment of the peer learning model. The importance of a cohesive relationship between students in peer learning is also highlighted by Sevenhuysen et al. (2014). However,Carrell et al. (2013) reports that students tend to gravitate towards others who are at the same education level to themselves rather than those at a more advanced level. This can impact on junior students' ability to interact effectively with their senior peer, potentially affecting learning outcomes. Moreover, in comparing the traditional model to the near-peer supervision model, Mamhidir et al. (2014) found clinical supervisors 
experienced stress when the junior student did not feel confident in their level of knowledge to be taught by the senior student.

There are positive outcomes for using the near-peer learning model in the supervision of undergraduate nursing students but also challenges. This said, it is important to explore and describe clinical facilitators' experiences of working with the near-peer learning model to get a better understanding in order to improve future model implementation.

\section{Methods}

A descriptive qualitative design was used to explore the experiences of clinical facilitators using the near-peer learning model. As there is a paucity of information on nearpeer learning from the perspectives of clinical facilitators, a qualitative design was deemed appropriate as it facilitates researchers to obtain rich data (Moretti et al., 2011) from participants that captures their experiences in a meaningful way (Streubert- Speziale \& Carpenter, 2011). To avoid preconceptions when collecting data, no theoretical framework or theory was used to guide the study.

\section{Setting}

The setting was two medical and two surgical wards in two Australian hospitals connected to the university. As the first-year students needed to practice foundation nursing skills and the third-year students needed to gain experience in leadership and delegation skills, the choice of two medical and two surgical wards was appropriate. Participants were expected to supervise both the first- year and third-year students simultaneously as the near-peer learning model required the third-year nursing student to supervise the first-year student. 


\section{Participants}

Purposeful sampling was used to recruit 11 clinical facilitator participants from these wards. To be included participants had to have experience in using the near-peer learning model. Participants were given an overview of the model by the researchers including the learning outcomes for the student dyad (first year paired with a third-year student). Participants were briefed by the researchers to discuss strategies for clinical teaching and giving feedback with the third-year students and explain to them their role and responsibilities when working with the first-year student.

\section{Data Collection}

Data were collected in October 2017 using a semi-structured interview guide. Two focus groups (three to five participants per group) and three individual interviews were conducted. The focus groups allowed participants to interact and share their experiences of using the model with others. The individual interviews were conducted as some participants were not able to join the focus groups due to work commitments. The focus groups lasted about an hour and the individual interviews were around 30 minutes. The interview questions centred around participants' experiences of facilitating the student dyad in the near-peer model, their perceived role in supporting student learning, barriers to and enhancers of using the model, the strategies they used for student facilitation and how the model could be improved. The same interview guide was used for both the focus group and individual interviews. The interviews were audio recorded and transcribed verbatim.

\section{Data Analysis}


The interviews were content analysed allowing the researchers to explore and describe the characteristics of the transcribed text and draw authentic inferences from the data to their context (Vaismoradi et al., 2013). The transcripts were independently read and re-read by all the researchers, who are experienced qualitative researchers, to familiarise themselves with the data and extract meaning units such as words, paragraphs and sentences that reflected the study aim. Then, similar meaning units were independently grouped into categories by the researchers. The categories were checked for exclusiveness with regards to the meaning units within them before being grouped into themes (Graneheim and Lundman, 2004_Bhattacharya, 2017).

\section{Methodological Considerations}

Trustworthiness of the data analysis was ensured by all three researchers independently reviewing the transcripts and developing codes, categories and themes. Subsequently, the researchers compared and discussed the codes until agreement was reached for the final codes that were clustered into categories and grouped into themes. This ensured inter-rater reliability. Further, to ensure the data were analysed within the context of possible codes/categories/themes rather than based on researchers' assumptions (one researcher had previously used the model) the research team reflected and diarised their assumptions about the model prior to collecting the data as supported by Enosh and Ben-Ari (2015). This activity provided credibility to the analysis process.

\section{Ethical Considerations}

Ethics approval was obtained from the University_Human Research Ethics Committee 
Paper for Nurse Education Today 2020

Committees (GUHREC 2017/656; HREC/17; QPAH/656).All participants were provided with an information sheet, freely volunteered to participate and signed a written consent form. Participants could withdraw their participation or refuse to answer any questions during data collection. Participants were assured that data would be kept confidential and stored in a secure password protected computer, accessible only to the researchers.

\section{Results}

Four themes describing clinical facilitators' experiences of the near-peer learning model are presented in Figure 1 below:

Put Figure 1: Clinical Facilitators' experiences on the near-peer model here

\section{Theme 1: Congruent student dyad characteristics}

Participants stated that the characteristics of the student dyad played an important role in how well the near-peer model worked. They stated students needed to be confident in their capacity to supervise and be supervised, adding that characteristics such as compatible personalities, trusting relationship, level of knowledge, the ability to give and receive feedback and willingness to work in the dyad are paramount. Participants reported that with the right match, the model was beneficial.

The model is about capacity and leadership building in the third years. It gives them accountability, increases that awareness and builds that bridge between being a student and becoming an RN and enculturing them into becoming work-ready ... the model 
allows first years to practice basic skills under the supervision of the third years ... it empowers both students (Participant 3, individual interview).

Some participants reported the model engendered nurturing by third-years and collegiality between the student dyad. They added that the nurturing they had observed in the near-peer learning model can lay the foundation for future registered nurses becoming collegial, supportive and nurturing towards each other.

Within nursing as a profession, you always hear this saying 'nurses eat their young', and it's true to a large degree. This model - is this potentially a way that we can generate at the training level the nurturing way of nursing where they nurture each other and continue to do so when they are registered (Participant 1, focus group).

However, participants reported conflict within the student dyad was challenging. It depends on personality. She [third year] was very good with the student but the first-year student took charge ... that was her personality (Participant 4, focus group). Another participant had a first-year student whom she found to be challenging when supervised by a third- year whose English was not their first language.

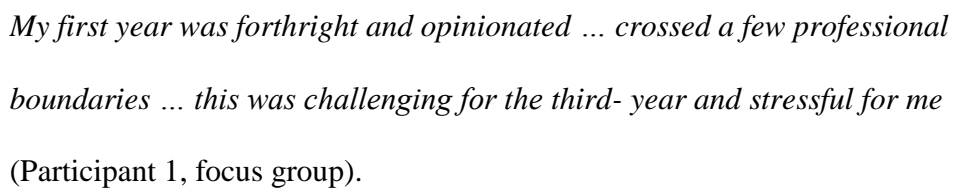

Whilst participants acknowledged third-year students were generally excellent with supervising first-years, they expressed concern about some third-year students' ability to give feedback to the first- year. Participants explained that as the student dyad had not developed a trusting relationship prior to being paired, giving and receiving feedback could be difficult for both students. 
The third year wasn't sure about giving the first-year feedback, and I said, “As long as it's professional, you give her feedback," but she wasn't comfortable (Participant 6, focus group).

Participants commented that they had observed some third-year students' inability to break down concepts to explain procedures such as correctly taking blood pressures/vital signs, doing urinalysis, activities of daily living such as showering patients and how to measure blood sugar level to the first-year students.

It comes down to giving the third-year a bit more education on how to break things down to teach the first- year. I found some third years struggling to teach (Participant 7 , focus group).

\section{Theme 2: Clinical facilitator attributes that support near-peer learning}

Participants discussed how they needed to feel confident with the level of knowledge of the student dyad when working with the model. Participants had to be sure that the first-year student was capable of performing foundation skills under the supervision of the third-year student. Others commented that when they observed the third-year student was not competent to supervise the first year they stepped in and gave extra support.

I was uncomfortable about having two students and when unsure of the capability of the third-year with the first-year student, I give extra support for the first year

(Participant 3, individual interview).

Participants stated that as they were accountable for the learning outcomes of the firstyear student, they needed to make sure the correct information was given by the third-year student. 
One third year was giving the first-year incorrect information which was a bad habit she had picked up ... so need to assess their level of knowledge to prevent this wrong info being passed on (Participant 1, individual interview).

Participants reported they needed to use their conflict resolution skills when difficulties arose with the student dyad. One participant stated third-year students were not always willing to supervise first- years because they were concerned about meeting their own learning needs whilst others observed that some first- years did not like to be supervised by a third- year because they wanted to work independently. This created time-consuming conflict that needed to be managed.

Some third-years were concerned of not meeting their expectations for placement because they were supervising the first year. They can be selfish, thinking, 'It's my last placement. I can't spare energy on somebody else' (Participant 5, focus group). My first year, was excellent but she has to feel the third-year can teach her. I think she felt hindered by her third year. She was like, "Well, I want to do this on my own, " and I'd have to say no to her and sort it out with both students that they are in this model and have to work together (Participant 5, focus group).

Debriefing the student dyad took extra time for participants as they debriefed the firstyear and third-year students separately. Participants explained how time management was needed to ensure both students had sufficient debriefing time to enhance learning outcomes.

The third years wanted to have their own debrief. They felt like there was an intruder [first-year], so I did a few debriefs with the first year on her own. This is extra time and you have to manage it so both students get the debrief (Participant 2, focus group). 
Paper for Nurse Education Today 2020

Participants explained how they juggled their time to try and give sufficient time to the third-year student as overseeing the first-year student simultaneously made it difficult.

I had to split myself in 20 different ways. I had to make sure I give the third year the time they need to do complex procedures whilst at the same time doing the meds with the first year ... they take a long time (Participant 7, focus group).

Theme 3: Suitability of the learning environment

Participants indicated that the required skills and knowledge to meet both students' needs have to be available. Some indicated that an acute hospital setting can be too complex for the first-year students who are normally sent to an aged care setting for their first clinical experience. Similarly, participants highlighted the fine line between third-year students engaging in higher level skills whilst at the same time supervising first-year students with foundation skills.

The concern I have was there wasn't a lot of personal care. A lot of the patients were independent. They missed out on basic cares which I think they do in the aged care facility. The third years also need to meet their outcomes whilst supervising first years with basic skills (Participant 8, focus group).

Two participants expressed concern about first year students being exposed to procedures that they had no theoretical knowledge about and questioned the suitability of the clinical environment in terms of meeting first-year learning outcomes.

A busy ward too fast for first-year student who may be exposed to [procedures] beyond their scope and they are missing out on stuff they should be doing at a slower pace (Participant 2, individual interview). 
Paper for Nurse Education Today 2020

Theme 4: Support for clinical facilitator

Participants suggested that support from the university and being well prepared on the theoretical and practical aspects of the model are essential for its smooth implementation. Participants stated they had little preparation time before the model was implemented and would have liked more information especially about working simultaneously with two different level students and ensuring their learning outcomes were met. One participant pointed out that not knowing the first-year student's scope of practice was difficult as in their ward they normally only had second and third-year students. This participant commented more support from the university was needed to brief them on how to ensure the first- year was effectively supervised by the third-year student.

Oh my God! I am going to have to manage two students! Need to step up and not just be assessing the third year. Having to deal with the additional component of how the third-years are working with the first-year, how they are teaching, whether they are being accurate ... need education in this new role (Participant 3 , individual interview).

Participants added that the university needed to better prepare the students on the model, especially in terms of facilitating some form of professional relationship development between first and third-year students. Participants recommended that at university during orientation both third and first-year students could be introduced to each other to provide the opportunity for students to get to know each other prior to clinical practice.

Need lead in time and establishing a relationship with the students prior ... at orientation day (Participant 3, individual interview). 


\section{Discussion}

In this study, facilitators found the near-peer learning model promoted the acquisition of leadership, accountability and mentoring skills including preparing third-year students to become work-ready whilst assisting first-year students to practise foundation skills and gain confidence, which is congruent with existing studies (Palsson et al.,2017., Silberberg et al. 2013., Stone et al. 2013). These positive outcomes may be explained by Bandura's (1979) social learning theory where the student peers, through meaningful interaction with each other, had learned from each other. Vygotsky's (1978) zone of proximal development theory may also be applied where learning from a senior peer may provide a safe psychological space for the first-year student as also reported in studies by Chou et al. (2011) and Yardley et al. (2012).

An interesting benefit highlighted in the current study was that the near-peer model brought out the nurturing trait in some third-year students. The facilitators mentioned how 'nurses eat their young' and indicated this switch to a nurturing role could potentially bring about future change in the workplace, especially in preventing horizontal violence and bullying as also reported by Anderson and Morgan (2017). The facilitators suggested the model can serve as a training ground to promote civility among students who will become future registered nurses.

Facilitators indicated that the near-peer model empowered both students in the dyad and helped first- years practice their foundation skills. However, a caveat perceived by the facilitators for the optimum delivery of the model was that the student dyad needs to be compatible. Personality differences and unwillingness of one or both students to work together that give rise to trust issues were mentioned as barriers. In a study conducted by Nygren and Carlson (2017) on near- peer learning, preceptors found personality differences and lack of 
cooperation between the student dyad had led to conflict, which was considered to be a negative aspect of peer learning and caused stress and more work for preceptors. Stenberg and Carlson (2015) also found conflicts arose in near- peer learning because of the differences in education levels and personalities between the students. Similarly, facilitators in this current study experienced stress when they had to deal with student conflict and manage their time so that they could give sufficient time to both students. The facilitators suggested that the university orientate first and third-year students together to facilitate relationship building so that when they are paired for the model, they are at least familiar with each other. Nygren and Carlson (2017) concur stating that students need to be better prepared through education prior to engaging in the near- peer learning model.

Although facilitators mentioned the excellent performance of some third-year students, they were concerned about the level of knowledge and capacity of a couple of students to teach first- years, including one participant observing the third-year student giving the wrong information to the first- year. This situation created stress for the facilitator as they were accountable for the learning outcomes of the first-year student as also found in Mamhidir et al. (2014) study (Mamhidir et al., 2014). In such circumstances the facilitator stepped in and gave extra support to the first-year student, which took time. The facilitators suggested that the third years be given some form of structural tool on how to teach to help them better impart knowledge to the first-year student as well as how to give effective feedback as some facilitators were unsure about the third years having the skills to give feedback. Sevenhuysen et al. (2015) also found student feedback lacked depth due to their inexperience leading to ineffective feedback.

The suitability of the learning environment with regards to both students being exposed to the required skills for their level was of concern to some facilitators. Facilitators mentioned how some fast-paced wards were not suitable for first-year students because of several reasons 
such as the ward lacking in basic care skills, procedures beyond their scope of practice and not having a slower pace to learn. For the third-year students, the facilitators were concerned they may miss out on higher level procedures because they were occupied in supervising first-years. The facilitators suggested that the wards are selected carefully to ensure both students are able to meet their learning objectives.

More support from the university staff and having a comprehensive understanding of the near -peer model was mentioned by facilitators. Although, the facilitators had been given information about the model, they expressed the need for more in-depth education including mentoring from university staff about student issues that may arise such as students not wanting to work cooperatively, to reduce their stress. Facilitators needing continued support from university faculty during model implementation aligns with findings from similar studies (Nygren and Carlson., Stenberg and Carlson, 2015) that also found adequate preparation reduced facilitator stress.

\section{Limitations}

The findings of this study depicts only the views of a small sample of 11 clinical facilitators working in a two medical/surgical wards. Further research with clinical facilitator participants working in a wider range of practice settings need to be conducted. As there is a dearth of information on clinical facilitator views on using the near-peer model, it is important to glean further evidence to gain a better understanding of the optimum application of the near-peer model in the clinical education of nursing students.

\section{Conclusion}


Our findings add to the existing literature on the experiences of clinical facilitators using the near-peer learning model, which can help others to better plan and implement the model in the future. Some factors that need to be considered include careful selection of student dyads, making sure the clinical environment is appropriate for both students to achieve their learning outcomes, and better preparation on the model and support for clinical facilitators to effectively facilitate students participating in the model.

\section{Reference}

Anderson, L.B., Morgan, M., 2017. An examination of nurses' intergenerational communicative experiences in the workplace: do nurses eat their young? Community Quarterly, 65 (4), 377-401.

Bandura, A. 1979. Social Learning Theory. Prentice Hall, Englewood Cliffs.

Bhattacharya, K. 2017. Fundamentals of Qualitative Research: A Practical Guide. Taylor \& Francis, Routledge, London, pp. 149-169.

Blomberg, K., Bisholt B., Kullén Engström, A., Ohlsson, U., Sundler Johansson, A., Gustafsson, M., 2014. Swedish nursing students' experience of stress during clinical setting characteristics and the organization of the clinical education. J. Clin. Nurs. 23 (15-16), 2264-2271.

Boud, D., 2001. Introduction: making the move to peer learning. In D. Boud, R., Cohen, R., J. Sampson. (Eds.). Peer Learning in Higher Education Learning From \& With Each Other, Kogan page, London, pp. 1-17. 
Buell, K., Pitts, W., Edmondson, M., Chu Ann., 2018. Comparing a centralised institutional and student-run peer-assisted learning program in medicine. Education for Health, 31 (2), 134-135.

Carrell, S.E., Sacerdote, B.I., West, J.E., 2013. From natural variation to optimal policy? The importance of endogenous peer group formation. Econometrica, 81: 855- 882.

Chou, C.L., Johnston, C.B., Singh, B., Garber, J.D., Kaplan, E., Lee, K., Teherani, A., 2011. A safe space for learning and reflection: one school's design for continuity with a peer group across clinical clerkships. Academ. Med. 86 (12), 1560-1565.

Durán, C.E., Bahena, E.N., Rodrígue, Mde L, Baca G.J, Uresti, A.S., Elizondo- Omaña R.E., López, S.G., 2012. Near- peer teaching in an anatomy course with a low faculty- to- student ratio. Anat. Sci. Educ. 5, 171- 176.

Edgar, S., Connaughton, J., 2014. Exploring the role and skill set of physiotherapy clinical educators in work integrated learning. Asia-Pacific Journal of Cooperative Education. $15(1), 29-36$.

Enosh, S., \& Ben- Ari, A., 2016. Reflexivity: The creation of liminal spaces- researchers, participants, and research encounters. Qual. Health. Res. 26( 4), 578-584.

Graneheim, U.H., Lundman, B., 2004. Qualitative content analysis in nursing research: concepts, procedures and measures to achieve trustworthiness. Nurse Educ. Today, 24 (2), 105112 .

Mamhidir, A.G., Kristofferzon, M.L., Hellstrom, H.E., Persson, E., Martensson., 2014.

Nursing preceptors' experiences of two clinical education models. Nurse Education in Practice, 14 (4), 427-433. DOI:10.1016/j.nepr.2014.01.010 
McKenna, L., Williams, B., 2017. The hidden curriculum in near-peer learning: an exploratory qualitative study. Nurse Educ. Today, 50,77-81. https://doi.org/10.1016/j.nedt.2016.12.010

Moretti, F., van Vliet, L., Bensing, J., Deledda, G., Mazzi, M., Rimondini, M., Fletcher, I., 2011. A standardized approach to qualitative content analysis of focus group discussions from different countries. Patient Educ. Couns. 82 (3), 420-428.

Nygren, F., Carlson, E., 2017. Preceptor' conceptions of a peer learning model: a phenomenographic study. Nurse Educ. Today, 49, 12-16.

Palsson, Y., Martensson, G., Swenne, C.L., Adel, E., Engstrom, M., 2017. A peer learning intervention for nursing students in clinical practice education: a quasi-experimental study. Nurse Educ. Today, 51, 81-87.

Riese, H., Samara A., Lillejord, S. 2012. Peer relations in peer learning. Int. J. Qual. Studies Educ. 25 (5), 601-624. http://doi.org/10.1080/09518398.2011.605078

Sevenhuysen, S., Skinner, E.H., Farlie, M.K., Raitman, L., Nickson, W., Keating, J.L., et al. 2015. Educators and students prefer traditional clinical education to a peer-assisted learning model despite similar student performance outcomes: a randomised trial. J Physiother. 60,209-16.

Silverberg, P., Ahern, C., van de Mortel, T., 2013. Learner and teachers in general practice: stakeholders views of the benefits and issues, Educ. Prim. Care, 24, 410-417.

Stenberg, M. \& Carlson, E., 2015. Swedish student nurses' perception of peer learning as an educational model during clinical practice in a hospital setting: an evaluation study. BMC Nurs. 14 (48), 1. 
Paper for Nurse Education Today 2020

Stone, R., Cooper, S., Cant, R., 2013. The value of peer learning in undergraduate nursing education: a systematic review. I/930901.SRN Nursing, 1-10 http://dx.doi.org/10.1155/2013

Streubert- Speziale, H.J., Carpenter, D.R. 2011.07. Qualitative research in nursing: Advancing the humanistic imperative. Lippincott Williams \& Wilkins, Philadelphia, PA.

Tai, J.H.M., Haines, T.P., Canny, B.J., Molloy, E.K., 2014. A study of medical students' peer learning on clinical placements: what they have taught themselves to do. J. Peer Learning, 7, 57-80.

Vygotsky, L.S., 1978. Mind in Society. In M. Cole., V, John-Stiener., Scribner., E. Souberman (Eds.). Harvard University Press, Cambridge, MA.

Vaismoradi, MTurunen, H., Bondas, T., 2013. Content analysis and thematic analysis: implications for conducting a qualitative descriptive study. Nurs. Health Sci.15 (3), 398-405.

Weyrich, P., Schrauth, M., Kraus, B., Habermehl, D., Netzhammer, N., Zipfel, S., Nikendei, C., 2008. Undergraduate technical skills training guided by student tutors: analysis of tutors' attitudes, tutees' acceptance and learning progress in an innovative teaching model. BMC Med. Educ. 8. Retrieved from http://www.biomedcentral.com/1472$6920 / 8 / 18$

Yardley, S., Teunissen, P.W., Doran, T., 2012. Experimental learning: AMEE Guide No 63. Med. Teach. 34 (2), e102-115. 


\section{Paper for Nurse Education Today 2020}


Paper for Nurse Education Today 2020

\begin{abstract}
Background: To mitigate escalating costs in clinical supervision of undergraduate nursing students and alleviate clinical facilitators' teaching burden, the near-peer learning model has become popular. Studies on near-peer learning have been on students' views of the model with a paucity of literature on clinical facilitators' experiences.
\end{abstract}

Aim: To explore clinical facilitator experiences of the near-peer learning model.

Design: A qualitative descriptive design was used with a purposeful sample of clinical facilitators involved in near-peer learning of nursing students.

Setting: Two teaching hospitals participated. Two medical and two surgical wards were selected from each.

Participants: Eleven clinical facilitators who had experienced using near-peer learning.

Methods: Focus group and individual interviews were conducted with clinical facilitators using a semi-structured interview guide following ethics approval. Data were analysed using content analysis.

Results: Four themes emerged: 1) Congruent student dyad characteristics 2) Clinical facilitator attributes of confidence in students' knowledge and effective time and conflict management, 3) Availability of suitable skills, and 4) Facilitator support and preparation on the model. These themes appear to promote optimum learning outcomes of the near-peer model including empowering students, junior students gaining practice in foundation skills and senior students gaining competence in leadership, mentoring and nurturing skills. Barriers included incongruent student characteristics resulting in conflict and trust issues, senior student not knowing how to teach, give feedback or teaching inaccurate information; facilitator's lack of 
confidence in students' knowledge level, inadequate time to manage the student dyad and resolve conflict; inadequate support and preparation from university staff; and unavailability of suitable skills.

Conclusion: Successful implementation requires careful selection of student dyads, appropriate clinical environment and support for clinical facilitators. Our findings provide a better understanding of the near-peer model for future implementation. 


\section{Introduction}

Little research exists on clinical facilitators' experience of using near-peer learning in nurse education. Whilst peer learning has been popular in medical education, nursing schools are beginning to use peer learning (Buell et al., 2018). This may be due to the escalating costs of clinical supervision leading to increases in the clinical facilitator to student ratio, potentially impacting on the quality of supervision and learning outcomes (Sevenhuysen et al., 2015).

Many terms are interchangeably used in the literature to describe peer learning such as 'cooperative learning, peer mentoring, peer coaching, team learning, near-peer learning, peer tutoring and peer-assisted learning' (Stone et al., 2013, p. 1), this study uses the term near peerlearning, which involves a student from the same program teaching a student who is at a lower level in their education (McKenna and Williams, 2017). While there are studies on students' perspectives of near-peer learning, there is a paucity of research on clinical facilitators' perspectives of using this model with undergraduate nursing students. Clinical facilitators are the link between universities and the clinical environment and play a role in teaching clinical skills and supporting students to meet registration standards (Edgar \& Connaughton, 2014). It is important to understand clinical facilitators' views on near-peer learning to provide a comprehensive account to improve its implementation.

\section{Background}

As the number of students entering nursing continue to rise, nursing schools are beginning to use near-peer learning as an adjunct to standard supervision models. The nearpeer learning model involves senior students teaching junior students from the same education program (McKenna and Williams, 2017). In the model, the clinical facilitator takes on a supportive and an overseer role (Palsson et al., 2017). Literature suggests that the near-peer 
model helps to improve learning outcomes for junior students and promotes communication and leadership skills in senior students (Silberberg et al., 2013). Blomberg et al. (2014) report that junior students' stress levels also reduce through working with senior peers (Stenberg and Carlson, 2015).

Near-peer learning encompasses aspects of social learning theory (Bandura, 1979) and Vygotsky's social interaction and the zone of proximal development constructivist theory (1978). The focus of social learning theory is that people learn through interaction with others and that learning is reciprocal (Bandura, 1979). Vygotsky (1978) focuses on the sociocultural context and the connections between people. Within the clinical environment, the sociocultural context can facilitate the sharing of experiences between students making concepts easier to understand than if they are instructed by a skilled teacher. Tai et al. (2014) explain this is because junior students are more open to learning from a senior peer who has already achieved the competency in the skill the junior student is trying to learn. Vygotsky reports how learning occurs in the zone of proximal development - defined as the difference between what the learner can do independently and what they can do under the guidance of a skilled teacher or through collaboration with a senior peer (Tai et al., 2014).

Studies on near-peer learning have been based on the views of students and only a few have focused on the views of clinical facilitators. A study by Sevenhuysen et al. (2014) compared physiotherapy clinical educators' views on near-peer learning compared to the traditional model of clinical teaching where one teacher is responsible for a designated group of students at the same educational level. Clinical educators found near-peer learning reduced teaching burden as students could ask their peers questions about patient care. This provided educators downtime to concentrate on other aspects of their work. The educators reported nearpeer learning helped students to develop skills in collaboration (Sevenhuysen et al., 2014), 
which they perceived to be valuable upon registration. Although feedback given by the peer teacher was viewed as beneficial, clinical educators in Sevenhuysen's study reported that peer feedback can be superficial and lack relevance, which can negatively impact student learning outcomes. Tai et al. (2014) concur, expressing reservations about student peer teachers' ability to give feedback to the student peer. Weyrich et al. (2008) add that near-peer learning may strain friendships between students and promote competition rather than collaboration although Durán et al. (2012) argue that competition may not be an issue when the student dyad is at different levels of education.

Despite literature highlighting how peer teaching enhances student learning and reduces clinical facilitator teaching load, Stone et al. (2013) stress student supervision by facilitators is important. Supervision can provide a safety net when the student peer cannot pass accurate information to their peer or does not possess suitable teaching skills, which could potentially impact on the provision of safe patient care (Stone et al., 2013). Riese et al. (2012) found that for peer learning to be useful the relationship between the student dyad needs to be considered and be integral to the deployment of the peer learning model. The importance of a cohesive relationship between students in peer learning is also highlighted by Sevenhuysen et al. (2014). Carrell et al. (2013) report that students tend to gravitate towards others who are at the same education level to themselves rather than those at a more advanced level. This can impact on junior students' ability to interact effectively with their senior peer, potentially affecting learning outcomes. Moreover, in comparing the traditional model to the near-peer supervision model, Mamhidir et al. (2014) found clinical supervisors experienced stress when the junior student did not feel confident in their level of knowledge to be taught by the senior student.

There are positive outcomes for using the near-peer learning model in the supervision of undergraduate nursing students but also challenges. This said, it is important to explore and 
describe clinical facilitators' experiences of working with the near-peer learning model to get a better understanding in order to improve future model implementation.

\section{Methods}

A descriptive qualitative design was used to explore the experiences of clinical facilitators using the near-peer learning model. As there is a paucity of information on nearpeer learning from the perspectives of clinical facilitators, a qualitative design was deemed appropriate as it facilitates researchers to obtain rich data (Moretti et al., 2011) from participants that captures their experiences in a meaningful way (Streubert- Speziale \& Carpenter, 2011). To avoid preconceptions when collecting data, no theoretical framework or theory was used to guide the study.

\section{Setting}

The setting was two medical and two surgical wards in two Australian hospitals connected to the university. As the first-year students needed to practice foundation nursing skills and the third-year students needed to gain experience in leadership and delegation skills, the choice of two medical and two surgical wards was appropriate. Participants were expected to supervise both the first- year and third-year students simultaneously as the near-peer learning model required the third-year nursing student to supervise the first-year student.

\section{Participants}

Purposeful sampling was used to recruit 11 clinical facilitator participants from these wards. To be included participants had to have experience in using the near-peer learning model. Participants were given an overview of the model by the researchers including the 
learning outcomes for the student dyad (first year paired with a third-year student). Participants were briefed by the researchers to discuss strategies for clinical teaching and giving feedback with the third-year students and explain to them their role and responsibilities when working with the first-year student.

\section{Data Collection}

Data were collected in October 2017 using a semi-structured interview guide. Two focus groups (three to five participants per group) and three individual interviews were conducted. The focus groups allowed participants to interact and share their experiences of using the model with others. The individual interviews were conducted as some participants were not able to join the focus groups due to work commitments. The focus groups lasted about an hour and the individual interviews were around 30 minutes. The interview questions centred around participants' experiences of facilitating the student dyad in the near-peer model, their perceived role in supporting student learning, barriers to and enhancers of using the model, the strategies they used for student facilitation and how the model could be improved. The same interview guide was used for both the focus group and individual interviews. The interviews were audio recorded and transcribed verbatim.

\section{Data Analysis}

The interviews were content analysed allowing the researchers to explore and describe the characteristics of the transcribed text and draw authentic inferences from the data to their context (Vaismoradi et al., 2013). The transcripts were independently read and re-read by all the researchers, who are experienced qualitative researchers, to familiarise themselves with the data and extract meaning units such as words, paragraphs and sentences that reflected the study aim. Then, similar meaning units were independently grouped into categories by the 
researchers. The categories were checked for exclusiveness with regards to the meaning units within them before being grouped into themes (Bhattacharya, 2017).

\section{Methodological Considerations}

Trustworthiness of the data analysis was ensured by all three researchers independently reviewing the transcripts and developing codes, categories and themes. Subsequently, the researchers compared and discussed the codes until agreement was reached for the final codes that were clustered into categories and grouped into themes. This ensured inter-rater reliability. Further, to ensure the data were analysed within the context of possible codes/categories/themes rather than based on researchers' assumptions (one researcher had previously used the model) the research team reflected and diarised their assumptions about the model prior to collecting the data as supported by Enosh and Ben-Ari (2015). This activity provided credibility to the analysis process.

\section{Ethical Considerations}

Ethics approval was obtained from the University Human Research Ethics Committee (Approval No. 2017/656) to conduct the study. All participants were provided with an information sheet, freely volunteered to participate and signed a written consent form. Participants could withdraw their participation or refuse to answer any questions during data collection. Participants were assured that data would be kept confidential and stored in a secure password protected computer, accessible only to the researchers. 


\section{Results}

Four themes describing clinical facilitators' experiences of the near-peer learning model are presented in Figure 1 below:

Put Figure 1: Clinical Facilitators' experiences on the near-peer model here

\section{Theme 1: Congruent student dyad characteristics}

Participants stated that the characteristics of the student dyad played an important role in how well the near-peer model worked. They stated students needed to be confident in their capacity to supervise and be supervised, adding that characteristics such as compatible personalities, trusting relationship, level of knowledge, the ability to give and receive feedback and willingness to work in the dyad are paramount. Participants reported that with the right match, the model was beneficial.

The model is about capacity and leadership building in the third years. It gives them accountability, increases that awareness and builds that bridge between being a student and becoming an RN and enculturing them into becoming work-ready ... the model allows first years to practice basic skills under the supervision of the third years ... it empowers both students (Participant 3, individual interview).

Some participants reported the model engendered nurturing by third-years and collegiality between the student dyad. They added that the nurturing they had observed in the near-peer learning model can lay the foundation for future registered nurses becoming collegial, supportive and nurturing towards each other.

Within nursing as a profession, you always hear this saying 'nurses eat their young', and it's true to a large degree. This model - is this potentially a way that we can 
generate at the training level the nurturing way of nursing where they nurture each other and continue to do so when they are registered (Participant 1, focus group).

However, participants reported conflict within the student dyad was challenging.

It depends on personality. She [third year] was very good with the student but the first-year student took charge ... that was her personality (Participant 4, focus group).

Another participant had a first-year student whom she found to be challenging when supervised by a third- year whose English was not their first language.

My first year was forthright and opinionated ... crossed a few professional boundaries ... this was challenging for the third-year and stressful for me (Participant 1, focus group).

Whilst participants acknowledged third-year students were generally excellent with supervising first-years, they expressed concern about some third-year students' ability to give feedback to the first- year. Participants explained that as the student dyad had not developed a trusting relationship prior to being paired, giving and receiving feedback could be difficult for both students.

The third year wasn't sure about giving the first-year feedback, and I said, "As long as it's professional, you give her feedback," but she wasn't comfortable (Participant 6, focus group).

Participants commented that they had observed some third-year students' inability to break down concepts to explain procedures such as correctly taking blood pressures/vital signs, doing urinalysis, activities of daily living such as showering patients and how to measure blood sugar level to the first-year students. 
Paper for Nurse Education Today 2020

It comes down to giving the third-year a bit more education on how to break things down to teach the first-year. I found some third years struggling to teach (Participant 7, focus group).

\section{Theme 2: Clinical facilitator attributes that support near-peer learning}

Participants discussed how they needed to feel confident with the level of knowledge of the student dyad when working with the model. Participants had to be sure that the first-year student was capable of performing foundation skills under the supervision of the third-year student. Others commented that when they observed the third-year student was not competent to supervise the first year they stepped in and gave extra support.

I was uncomfortable about having two students and when unsure of the capability of the third-year with the first-year student, I give extra support for the first year

(Participant 3, individual interview).

Participants stated that as they were accountable for the learning outcomes of the firstyear student, they needed to make sure the correct information was given by the third-year student.

One third year was giving the first-year incorrect information which was a bad habit she had picked up ... so need to assess their level of knowledge to prevent this wrong info being passed on (Participant 1, individual interview).

Participants reported they needed to use their conflict resolution skills when difficulties arose with the student dyad. One participant stated third-year students were not always willing to supervise first- years because they were concerned about meeting their own learning needs whilst others observed that some first- years did not like to be supervised by a third- year 
because they wanted to work independently. This created time-consuming conflict that needed to be managed.

Some third-years were concerned of not meeting their expectations for placement because they were supervising the first year. They can be selfish, thinking, 'It's my last placement. I can't spare energy on somebody else' (Participant 5, focus group). My first year, was excellent but she has to feel the third-year can teach her. I think she felt hindered by her third year. She was like, "Well, I want to do this on my own, " and I'd have to say no to her and sort it out with both students that they are in this model and have to work together (Participant 5, focus group).

Debriefing the student dyad took extra time for participants as they debriefed the firstyear and third-year students separately. Participants explained how time management was needed to ensure both students had sufficient debriefing time to enhance learning outcomes.

The third years wanted to have their own debrief. They felt like there was an intruder [first-year], so I did a few debriefs with the first year on her own. This is extra time and you have to manage it so both students get the debrief (Participant 2, focus group).

Participants explained how they juggled their time to try and give sufficient time to the third-year student as overseeing the first-year student simultaneously made it difficult.

I had to split myself in 20 different ways. I had to make sure I give the third year the time they need to do complex procedures whilst at the same time doing the meds with the first year ... they take a long time (Participant 7, focus group). 
Paper for Nurse Education Today 2020

Theme 3: Suitability of the learning environment

Participants indicated that the required skills and knowledge to meet both students' needs have to be available. Some indicated that an acute hospital setting can be too complex for the first-year students who are normally sent to an aged care setting for their first clinical experience. Similarly, participants highlighted the fine line between third-year students engaging in higher level skills whilst at the same time supervising first-year students with foundation skills.

The concern I have was there wasn't a lot of personal care. A lot of the patients were independent. They missed out on basic cares which I think they do in the aged care facility. The third years also need to meet their outcomes whilst supervising first years with basic skills (Participant 8, focus group).

Two participants expressed concern about first year students being exposed to procedures that they had no theoretical knowledge about and questioned the suitability of the clinical environment in terms of meeting first-year learning outcomes.

\begin{abstract}
A busy ward too fast for first-year student who may be exposed to [procedures] beyond their scope and they are missing out on stuff they should be doing at a slower pace (Participant 2, individual interview).
\end{abstract}

\title{
Theme 4: Support for clinical facilitator
}

Participants suggested that support from the university and being well prepared on the theoretical and practical aspects of the model are essential for its smooth implementation. Participants stated they had little preparation time before the model was implemented and would have liked more information especially about working simultaneously with two different 
level students and ensuring their learning outcomes were met. One participant pointed out that not knowing the first-year student's scope of practice was difficult as in their ward they normally only had second and third-year students. This participant commented more support from the university was needed to brief them on how to ensure the first- year was effectively supervised by the third-year student.

Oh my God! I am going to have to manage two students! Need to step up and not just be assessing the third year. Having to deal with the additional component of how the third-years are working with the first-year, how they are teaching, whether they are being accurate ... need education in this new role (Participant 3 , individual interview).

Participants added that the university needed to better prepare the students on the model, especially in terms of facilitating some form of professional relationship development between first and third-year students. Participants recommended that at university during orientation both third and first-year students could be introduced to each other to provide the opportunity for students to get to know each other prior to clinical practice.

Need lead in time and establishing a relationship with the students prior ... at orientation day (Participant 3, individual interview).

\section{Discussion}

In this study, facilitators found the near-peer learning model promoted the acquisition of leadership, accountability and mentoring skills including preparing third-year students to become work-ready whilst assisting first-year students to practise foundation skills and gain confidence, which is congruent with existing studies (Palsson et al.,2017., Silberberg et al. 
2013., Stone et al. 2013). These positive outcomes may be explained by Bandura's (1979) social learning theory where the student peers, through meaningful interaction with each other, had learned from each other. Vygotsky's (1978) zone of proximal development theory may also be applied where learning from a senior peer may provide a safe psychological space for the first-year student as also reported in studies by Chou et al. (2011) and Yardley et al. (2012).

An interesting benefit highlighted in the current study was that the near-peer model brought out the nurturing trait in some third-year students. The facilitators mentioned how 'nurses eat their young' and indicated this switch to a nurturing role could potentially bring about future change in the workplace, especially in preventing horizontal violence and bullying as also reported by Anderson and Morgan (2017). The facilitators suggested the model can serve as a training ground to promote civility among students who will become future registered nurses.

Facilitators indicated that the near-peer model empowered both students in the dyad and helped first- years practice their foundation skills. However, a caveat perceived by the facilitators for the optimum delivery of the model was that the student dyad needs to be compatible. Personality differences and unwillingness of one or both students to work together that give rise to trust issues were mentioned as barriers. In a study conducted by Nygren and Carlson (2017) on near- peer learning, preceptors found personality differences and lack of cooperation between the student dyad had led to conflict, which was considered to be a negative aspect of peer learning and caused stress and more work for preceptors. Stenberg and Carlson (2015) also found conflicts arose in near- peer learning because of the differences in education levels and personalities between the students. Similarly, facilitators in this current study experienced stress when they had to deal with student conflict and manage their time so that they could give sufficient time to both students. The facilitators suggested that the university orientate first and third-year students together to facilitate relationship building so 
that when they are paired for the model, they are at least familiar with each other. Nygren and Carlson (2017) concur stating that students need to be better prepared through education prior to engaging in the near- peer learning model.

Although facilitators mentioned the excellent performance of some third-year students, they were concerned about the level of knowledge and capacity of a couple of students to teach first- years, including one participant observing the third-year student giving the wrong information to the first- year. This situation created stress for the facilitator as they were accountable for the learning outcomes of the first-year student as also found in Mamhidir et al. (2014) study. In such circumstances the facilitator stepped in and gave extra support to the first-year student, which took time. The facilitators suggested that the third years be given some form of structural tool on how to teach to help them better impart knowledge to the firstyear student as well as how to give effective feedback as some facilitators were unsure about the third years having the skills to give feedback. Sevenhuysen et al. (2015) also found student feedback lacked depth due to their inexperience leading to ineffective feedback.

The suitability of the learning environment with regards to both students being exposed to the required skills for their level was of concern to some facilitators. Facilitators mentioned how some fast-paced wards were not suitable for first-year students because of several reasons such as the ward lacking in basic care skills, procedures beyond their scope of practice and not having a slower pace to learn. For the third-year students, the facilitators were concerned they may miss out on higher level procedures because they were occupied in supervising first-years. The facilitators suggested that the wards are selected carefully to ensure both students are able to meet their learning objectives.

More support from the university staff and having a comprehensive understanding of the near -peer model was mentioned by facilitators. Although, the facilitators had been given 
information about the model, they expressed the need for more in-depth education including mentoring from university staff about student issues that may arise such as students not wanting to work cooperatively, to reduce their stress. Facilitators needing continued support from university faculty during model implementation aligns with findings from similar studies (Nygren and Carlson., Stenberg and Carlson, 2015) that also found adequate preparation reduced facilitator stress.

\section{Limitations}

The findings of this study depicts only the views of a small sample of 11 clinical facilitators working in a two medical/surgical wards. Further research with clinical facilitator participants working in a wider range of practice settings need to be conducted. As there is a dearth of information on clinical facilitator views on using the near-peer model, it is important to glean further evidence to gain a better understanding of the optimum application of the near-peer model in the clinical education of nursing students.

\section{Conclusion}

Our findings add to the existing literature on the experiences of clinical facilitators using the near-peer learning model, which can help others to better plan and implement the model in the future. Some factors that need to be considered include careful selection of student dyads, making sure the clinical environment is appropriate for both students to achieve their learning outcomes, and better preparation on the model and support for clinical facilitators to effectively facilitate students participating in the model. 


\section{Reference}

Anderson, L.B., Morgan, M., 2017. An examination of nurses' intergenerational communicative experiences in the workplace: do nurses eat their young? Community Quarterly, 65 (4), 377-401.

Bandura, A. 1979. Social Learning Theory. Prentice Hall, Englewood Cliffs.

Bhattacharya, K. 2017. Fundamentals of Qualitative Research: A Practical Guide. Taylor \& Francis, Routledge, London, pp. 149-169.

Blomberg, K., Bisholt B., Kullén Engström, A., Ohlsson, U., Sundler Johansson, A., Gustafsson, M., 2014. Swedish nursing students' experience of stress during clinical setting characteristics and the organization of the clinical education. J. Clin. Nurs. 23 (15-16), 2264-2271.

Buell, K., Pitts, W., Edmondson, M., Chu Ann., 2018. Comparing a centralised institutional and student-run peer-assisted learning program in medicine. Education for Health, 31 (2), 134-135.

Carrell, S.E., Sacerdote, B.I., West, J.E., 2013. From natural variation to optimal policy? The importance of endogenous peer group formation. Econometrica, 81: 855-882.

Chou, C.L., Johnston, C.B., Singh, B., Garber, J.D., Kaplan, E., Lee, K., Teherani, A., 2011. A safe space for learning and reflection: one school's design for continuity with a peer group across clinical clerkships. Academ. Med. 86 (12), 1560-1565.

Durán, C.E., Bahena, E.N., Rodrígue, Mde L, Baca G.J, Uresti, A.S., Elizondo- Omaña R.E., López, S.G., 2012. Near- peer teaching in an anatomy course with a low faculty- to- student ratio. Anat. Sci. Educ. 5, 171- 176. 
Edgar, S., Connaughton, J., 2014. Exploring the role and skill set of physiotherapy clinical educators in work integrated learning. Asia-Pacific Journal of Cooperative Education. $15(1), 29-36$.

Enosh, S., \& Ben- Ari, A., 2016. Reflexivity: The creation of liminal spaces- researchers, participants, and research encounters. Qual. Health. Res. 26( 4), 578- 584.

Mamhidir, A.G., Kristofferzon, M.L., Hellstrom, H.E., Persson, E., Martensson., 2014. Nursing preceptors' experiences of two clinical education models. Nurse Education in Practice, 14 (4), 427-433. DOI:10.1016/j.nepr.2014.01.010

McKenna, L., Williams, B., 2017. The hidden curriculum in near-peer learning: an exploratory qualitative study. Nurse Educ. Today, 50,77-81. https://doi.org/10.1016/j.nedt.2016.12.010

Moretti, F., van Vliet, L., Bensing, J., Deledda, G., Mazzi, M., Rimondini, M., Fletcher, I., 2011. A standardized approach to qualitative content analysis of focus group discussions from different countries. Patient Educ. Couns. 82 (3), 420-428.

Nygren, F., Carlson, E., 2017. Preceptor' conceptions of a peer learning model: a phenomenographic study. Nurse Educ. Today, 49, 12-16.

Palsson, Y., Martensson, G., Swenne, C.L., Adel, E., Engstrom, M., 2017. A peer learning intervention for nursing students in clinical practice education: a quasi-experimental study. Nurse Educ. Today, 51, 81-87.

Riese, H., Samara A., Lillejord, S. 2012. Peer relations in peer learning. Int. J. Qual. Studies Educ. 25 (5), 601-624. http://doi.org/10.1080/09518398.2011.605078 
Sevenhuysen, S., Skinner, E.H., Farlie, M.K., Raitman, L., Nickson, W., Keating, J.L., et al. 2015. Educators and students prefer traditional clinical education to a peer-assisted learning model despite similar student performance outcomes: a randomised trial. J Physiother. 60,209-16.

Silverberg, P., Ahern, C., van de Mortel, T., 2013. Learner and teachers in general practice: stakeholders views of the benefits and issues, Educ. Prim. Care, 24, 410-417.

Stenberg, M. \& Carlson, E., 2015. Swedish student nurses' perception of peer learning as an educational model during clinical practice in a hospital setting: an evaluation study. BMC Nurs. 14 (48), 1.

Stone, R., Cooper, S., Cant, R., 2013. The value of peer learning in undergraduate nursing education: a systematic review. I/930901.SRN Nursing, 1-10 http://dx.doi.org/10.1155/2013

Streubert- Speziale, H.J., Carpenter, D.R. 2011. Qualitative research in nursing: Advancing the humanistic imperative. Lippincott Williams \& Wilkins, Philadelphia, PA.

Tai, J.H.M., Haines, T.P., Canny, B.J., Molloy, E.K., 2014. A study of medical students' peer learning on clinical placements: what they have taught themselves to do. J. Peer Learning, 7, 57-80.

Vygotsky, L.S., 1978. Mind in Society. In M. Cole., V, John-Stiener., Scribner., E. Souberman (Eds.). Harvard University Press, Cambridge, MA.

Vaismoradi, MTurunen, H., Bondas, T., 2013. Content analysis and thematic analysis: implications for conducting a qualitative descriptive study. Nurs. Health Sci.15 (3), 398-405. 
Weyrich, P., Schrauth, M., Kraus, B., Habermehl, D., Netzhammer, N., Zipfel, S., Nikendei, C., 2008. Undergraduate technical skills training guided by student tutors: analysis of tutors' attitudes, tutees' acceptance and learning progress in an innovative teaching model. BMC Med. Educ. 8. Retrieved from http://www.biomedcentral.com/1472$6920 / 8 / 18$

Yardley, S., Teunissen, P.W., Doran, T., 2012. Experimental learning: AMEE Guide No 63. Med. Teach. 34 (2), e102-115. 


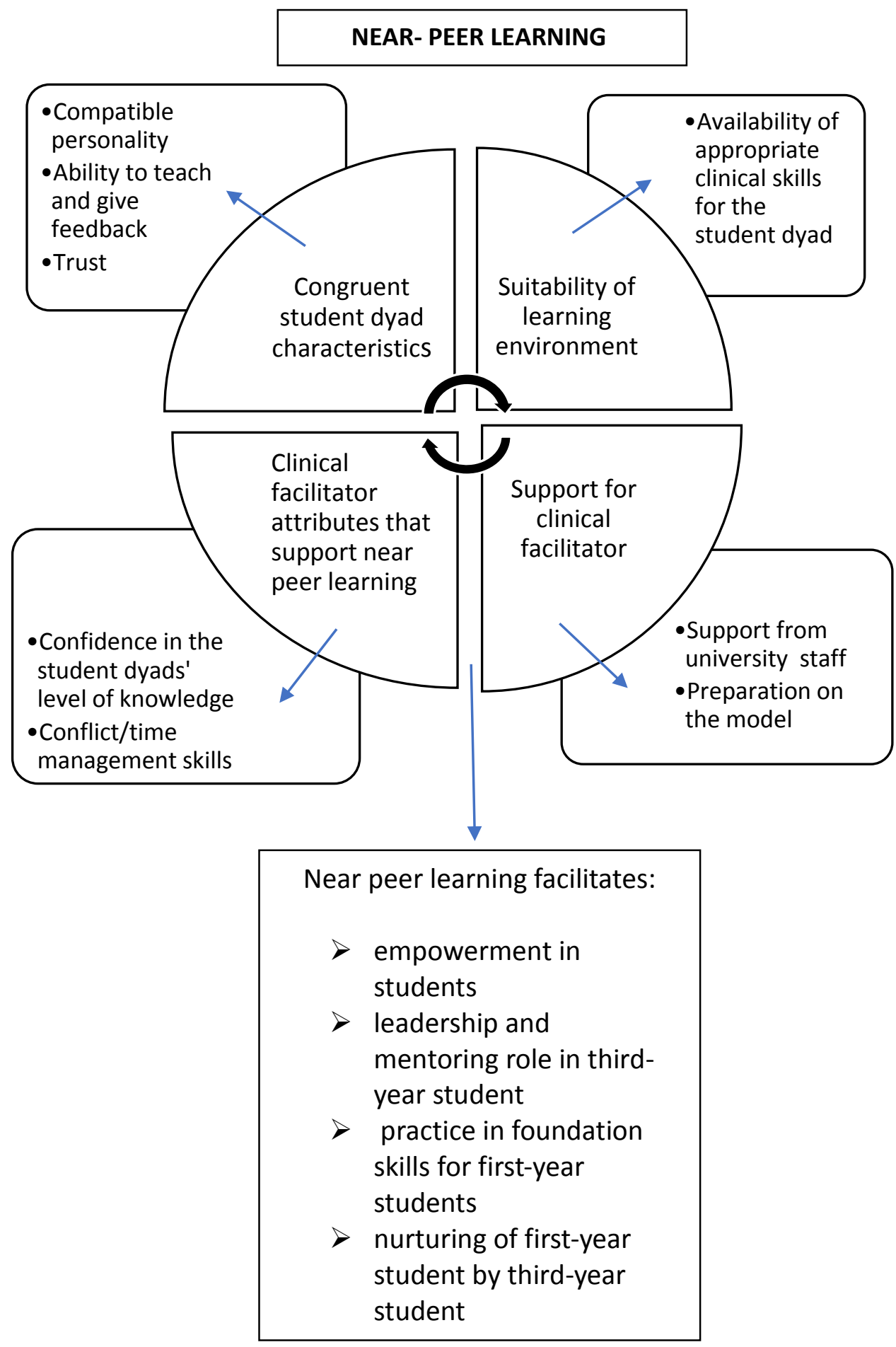

Figure 1. Clinical facilitators' experiences on the near-peer model 
CRediT Author Statement

Saras Henderson: Conceptualisation; Funding acquisition; Methodology; Data collection and analysis; Writing-Preparing the original draft of the manuscript; Editing, finalising and submitting the manuscript. Judith Needham: Conceptualisation; Funding acquisition, Methodology; Data collection and analysis; Reviewing and editing draft of the manuscript. Thea van de Mortel: Conceptualisation; Funding acquisition; Methodology; Data collection and analysis; Project administration (funding management); Reviewing and editing draft of the manuscript. 